\title{
Qualitative and Quantitative Phytochemical Analysis and Antioxidant Properties of Leaves and Stems of Clinacanthus nutans (Burm. f.) Lindau from Two Herbal Farms of Negeri Sembilan, Malaysia
}

\author{
H.S. Kong ${ }^{1}$, K.H. Musa ${ }^{2}$, Z. Mohd Kasim ${ }^{1}$ and N. Abdullah Sani ${ }^{*_{1}}$ \\ ${ }^{1}$ Centre for Biotechnology and Functional Food, Faculty of Science and Technology, \\ Universiti Kebangsaan Malaysia, 43600 UKM, Bangi Selangor, Malaysia \\ ${ }^{2}$ College of Agriculture and Veterinary Medicine, Qassim University, KSA
}

\begin{abstract}
The objective of the study is to analyse the phytochemical content by quantitative and qualitative methods and to investigate the antioxidant properties on Clinacanthus nutans leaves and stems from different areas: Yik Poh Ling (YPL) un-shaded sample (exposed to direct sunlight) and You Dun Chao (YDC) un-shaded and shaded (with black shade netting) samples. Extracts were prepared by dissolving fine powder of $C$. nutans in 1:10 solvent using ultrasonic extraction for an hour. Preliminary screening and quantitative estimation of phytochemical (alkaloids, flavonoids, cardiac glycosides, saponins, steroids, terpenoids, phenols and tannins) analysis were conducted. Then, determination of antioxidant properties (total phenolic content, TPC, ferric reducing/ antioxidant power, FRAP and radical-scavenging activities, DPPH) were conducted. All the samples contained alkaloids, flavonoids, cardiac glycosides, saponins, steroids, terpenoids, phenols and tannins. Un-shaded leaves of $C$. nutans from YDC exhibited significantly higher result in antioxidant properties (966.0omg GAE/g of dried sample in TPC, 20.44mg TE/g of dried sample in FRAP and $11.14 \mathrm{mg}$ TE/g of dried sample in DPPH) than the other samples $(\mathrm{p}<0.05)$. As a conclusion, $C$. nutans has a good potential to be an alternative antioxidant source.
\end{abstract}

Keywords: Clinacanthus nutans, Sabah Snake Grass, phytochemical, antioxidant, shaded and un-shaded

\section{INTRODUCTION}

Clinacanthus nutans is a native medicinal herb that grows in a tropical climate that mainly can be found in Malaysia and Thailand. It is a shrub green plant, which can be grown by stem propagation method. The $C$. nutans has been utilised for its benefits and functions according to folklore, especially in the Southeast Asia region. It was believed can treating skin rashes, gout and diabetes. The previous study showed the presence of different phytochemicals compound such as flavonoids and terpenoids in the plant. These phytochemical compounds contributed to its antioxidant properties of plants. Furthermore, it contributes to good health and disease prevention. The presence of phytochemical compounds also contributed to antibacterial and antifungal properties.

Glycosides involve enzyme hydrolysis and heart disease treatment. Saponins are plant-derived anti-inflammatory compounds, which lower blood cholesterol, prevent heart disease and cancers. Abaoba and Efuwape (2001) and Mohanta et al. (2007) claimed that saponins have antifungal properties. Steroids may decrease postoperative atrial fibrillation and inhibiting the inflammatory process post cardiopulmonary bypass, decrease capillary wall permeability, preventing and migration of inflammatory mediators into the systemic circulation (Kristeller et al., 2014). Terpenoids act as biological antioxidants to protect

*Corresponding author's e-mail: norrasani@ukm.edu.my 
cells or tissues from the damaging effect of free radicals (Prakash et al., 2004).

Tannins are potential metal ion chelators, protein precipitating agents, and biological antioxidants, which contribute to antitumor effects and astringent activity. Tannins also improve wound healing through protein precipitation (Okuda et al., 1995). De-Ruiz et al. (2001) and Elegani et al. (2002) stated that tannins (found in medicinal plants) are responsible in antiviral and antibacterial activities. Flavonoids were detected in all leaves extracts of the herbal plant (Siew et al., 2014; Sakdarat et al., 2009). Flavonoids are potent antioxidants agents and regulating activities of various enzyme systems due to their interaction with various biomolecules (Maldonado et al., 2003). Flavonoids are renowned for their free radical scavenging potency, which underline their antibacterial, anti-inflammatory, anti-thrombotic and vasodilatory activities (Yamamoto and Gaynor, 2002). The presence of flavonoids and saponins are contributing to traditional treatment (Othira et al., 2009; Zwadyk, 1992). Alkaloids is important as constitute potent therapeutic agents, possess anti-inflammatory, and antibacterial properties (Gao et al., 2015; Liu et al., 2015).

Antioxidant activity can be tested using total phenolic content (TPC), ferric reducing antioxidant power (FRAP) and 2, 2-diphenyl-1-picrylhydrazyl (DPPH) tests. The previous study showed that the radical scavenging activity of petroleum ether extracts of C. nutans was $82.00 \pm 0.02$ \% (Arullappan et al., 2014). Besides, the chloroform extract of $C$. nutans leaves was a good antioxidant agent against galvinoxyl radicals and 2, 2-diphenyl-1-picrylhydrazyl (DPPH). However, it was less effective in negating hydrogen peroxide radicals and nitric oxide (Yang et al., 2013).

Moreover, higher ferric reducing antioxidant power (FRAP) in six-month-old buds of $C$. nutans than onemonth-old buds were recorded with the denomination of $488 \mu \mathrm{M}$ of $\mathrm{Fe}(\mathrm{II}) / \mathrm{g}$ and $453 \mu \mathrm{M}$ of $\mathrm{Fe}(\mathrm{II}) / \mathrm{g}$ respectively (Fong et al., 2014). Medicinal plants contain plenty of chemical compounds (bioactive secondary metabolites such as terpenes, phenolics and alkaloids, from secondary plant metabolism), which is exhibiting different biological and pharmacological activities such as antimicrobial and antioxidant (Stefanović et al., 2015).

The previous study was focused more on leaves extract of C. nutans, and only certain phytochemical compounds were investigated such as flavonoids, alkaloids, phenol and saponin. This study focused on determining the presence of phytochemical via qualitative method, analysing the phytochemical content by quantitative methods and learning the antioxidant properties on C. nutans leaves and stems from two herbal farms of Negeri Sembilan, Malaysia: Yik Poh Ling (YPL) un-shaded samples ; You Dun Chao (YDC) un-shaded and shaded samples.

\section{MATERIALS AND METHODS}

\section{A. Plant material preparation}

Three-month-old fresh and healthy leaves and stems of Sabah snake grass (C. nutans) were obtained from Yik Poh Ling (YPL, in Senawang) and You Dun Chao (YDC, in Sendayan) Herbal Farms, in the state of Negeri Sembilan, Malaysia (Figure 1 and 2). The YPL had planted the $C$. nutans in un-shaded condition (exposed to direct sunlight) while YDC had planted $C$. nutans in shaded (with black shade netting) and un-shaded conditions (Figure 3). About $10 \mathrm{~kg}$ of the plant materials were collected from the farms. The leaves and stems were washed with water to remove sand and dust particles. The leaves and stems were then freeze-dried using ALPHA freeze dryer (ALPHA, Hampshire UK), homogenised into $0.5 \mathrm{~mm}$ size using Universal cutting mill (FRITSCH, Idar-Oberstein, Germany) before further analyses were conducted. The freeze-dried samples were stored in a freezer (ALPHA, Hampshire, UK) $\left(-20^{\circ} \mathrm{C}\right)$ for further use.

\section{B. Extraction of plant materials}

The method of Hassan et al. (2015) was used for the preparation of the plant materials of $C$. nutans (leaves and stems) and extracts with minor modifications. The $70 \%$ acetone (Merck, Germany) extracts were prepared by dissolving fine powder of $C$. nutans leaves and stems in 1:10 solvent using ultrasonic extraction for an hour. The extracts were then filtered with the aid of a Bucker funnel and Whatman filter paper \#1. The extracts were preserved in airtight bottles at $-40^{\circ} \mathrm{C}$ for further use. 


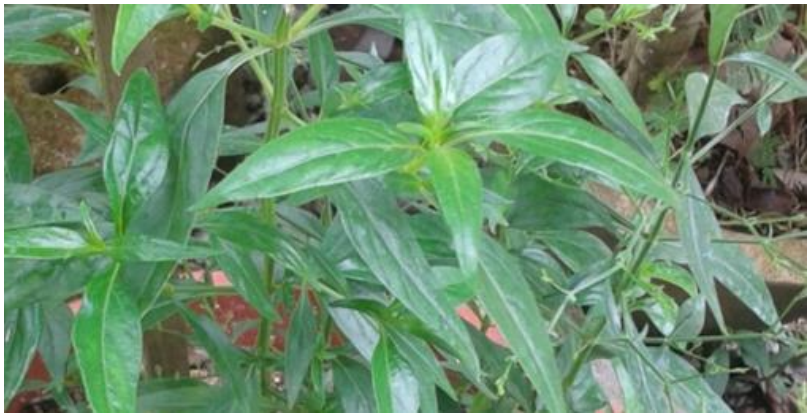

Figure 1. Leaves of Clinacanthus nutans

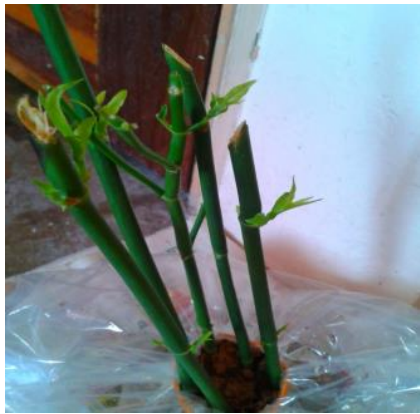

Figure 2. Stems of Clinacanthus nutans

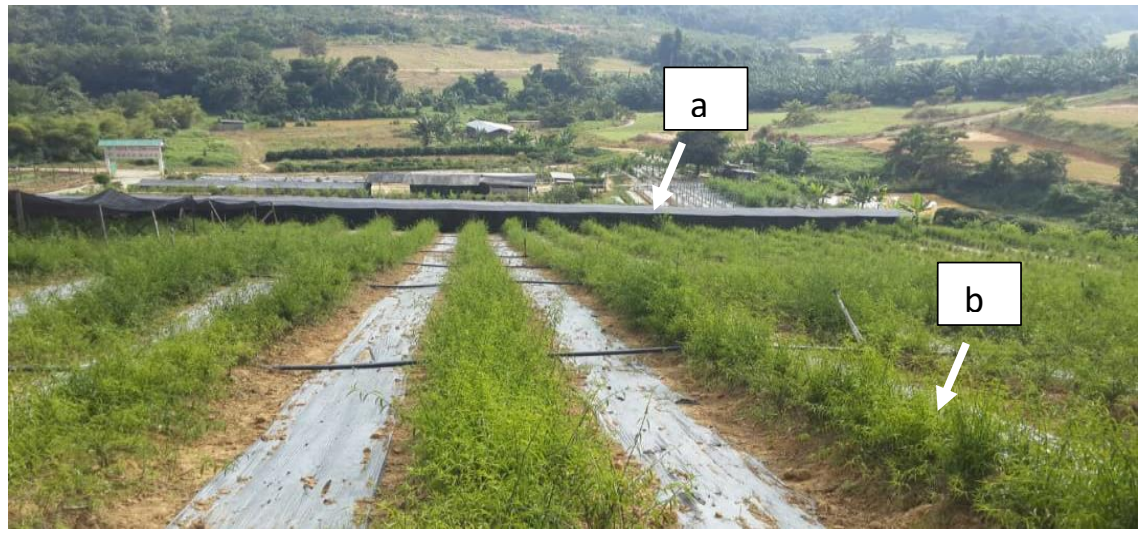

Figure 3. Shaded (a) and un-shaded (b) samples of Clinacanthus nutans

\section{Preliminary qualitative phytochemical analysis of C. nutans leaves and stems}

The qualitative phytochemical screening of the $C$. nutans leaves and stems extracts was performed using methods suggested by Sofowora (1993), Harborne (1984) and Trease and Evans (2002).

\section{Alkaloid test}

2mL of potassium iodide (Sigma-Aldrich, US) was mixed with $10 \mathrm{~mL}$ of the leaves and stems crude extracts, which forms brown precipitation with alkaloid solutions.

\section{Flavonoid test}

$2 \mathrm{~mL}$ of sodium hydroxide (2\%) (Sigma-Aldrich, US) was added to 10mL of the leaves and stems crude extracts, followed by a few drops of diluted sulphuric acid (10\%) (Sigma-Aldrich, US). The transformation from an intense red-orange colour to colourless indicated the presence of flavonoid.

\section{Cardiac glycoside test}

2mL of glacial acetic acid (Sigma-Aldrich, US) and one or two drops of $2 \%$ ferric chloride (Sigma-Aldrich, US) were mixed with $10 \mathrm{~mL}$ of the leaves and stem crude extracts. The mixtures were poured carefully into separate test tubes with $2 \mathrm{~mL}$ of concentrated sulphuric acid (Sigma-Aldrich, US). Cardiac glycoside was determined by the presence of a brown ring inter-phase in the mixtures.

\section{Phenol and tannin tests}

2mL of ferric chloride solution (2\%) (Sigma-Aldrich, US) was mixed with $10 \mathrm{~mL}$ of the leaves and stem crude extracts. The presence of phenol and tannin were determined by the changing of the mixture colour from blue-green to black.

\section{Saponin test}

$5 \mathrm{~mL}$ of distilled water was added to $10 \mathrm{~mL}$ of dilute the leaves and stems crude extracts $(100 \mu \mathrm{L}$ extract in $5 \mathrm{~mL}$ distilled water). The mixture was vigorously shaken, and the formation of stable foam determined the presence of saponin. 


\section{Steroid test}

$2 \mathrm{~mL}$ of acetic anhydride (Sigma-Aldrich, US) and sulphuric acid (Sigma-Aldrich, US) were added to $10 \mathrm{~mL}$ of the leaves and stems crude extracts on the sidewise of the test tube. The presence of steroid was determined when the samples colour change from violet to blue-green was observed.

\section{Terpenoid test}

$2 \mathrm{~mL}$ of chloroform (Sigma-Aldrich, US) was used to dissolve 10mL of the leaves and stems crude extracts and evaporated to dryness using a water bath (Memmert, Germany) (Boiling point for chloroform $=62^{\circ} \mathrm{C}$ ). $2 \mathrm{~mL}$ of concentrated sulphuric acid (Sigma-Aldrich, US) was added and heated for about 2 mins. The presence of terpenoid was determined when the mixture appeared in red.

\section{Quantitative phytochemical analysis of C. nutans leaves and stems}

\section{Total alkaloid determination}

The method of Harborne (1973) was used for this analysis. $5 \mathrm{~g}$ each of leaves or stems of $C$. nutans powder was mixed in a test tube with 200mL of ethanol (Sigma-Aldrich, US) and 10\% acetic acid (Sigma-Aldrich, US). The test tube was capped and left for 4 hours in room temperature. The mixture sample was filtered with filter paper Whatman No. $42(125 \mathrm{~mm})$, and the volume was reduced to a quarter of its original volume using a water bath (Memmert, Germany). $5 \mathrm{~mL}$ of concentrated ammonium hydroxide solution (Sigma-Aldrich, US) was added into the reduced mixture sample drop-wise until precipitation occurred. After filtration (using filter paper Whatman No. 42) and drying in an oven (Memmert, Germany) at $40^{\circ} \mathrm{C}$, the precipitate was collected and weighed. The percentage of the total alkaloid content was calculated as below:

Percentage of the total alkaloid (\%)

$$
=\frac{\text { Weight of residue }}{\text { Weight of the sample taken }} \times 100
$$

2. Cardiac glycoside determination

The method of El-Olemy, Al-Muhtadi dan Affi (1994) was adopted. About one $\mathrm{g}$ of the dried leaves or stems of $C$. nutans was weighed separately into different test tubes, and 10mL of ethanol (70\%) (Sigma-Aldrich, US) was placed into each test tube. The test tube was covered and placed in a shaker (Intertech, Taipei, Taiwan) and was shaken at 300 rpm for 6 hours at room temperature $\left(25^{\circ} \mathrm{C}\right)$. The mixture was filtered with Whatman No. 42 filter paper. The filtrate was treated with $5 \mathrm{~mL}$ distilled water, followed by $1 \mathrm{~mL}$ of $12.5 \%$ lead acetate (Sigma-Aldrich, US) to precipitate tannins, resins and pigments. Distilled water was added until the volume was $8 \mathrm{~mL}$ and shaken in a shaker set (Intertech, Taipei, Taiwan) at 300 rpm for 10 mins. $2 \mathrm{~mL}$ of 4.77\% disodium hydrogen phosphate $\left(\mathrm{Na}_{2} \mathrm{HPO}_{4}\right)$ solution (Sigma-Aldrich, US) was added to precipitate the excess phosphorus ions. The resultant solution was filtered with Whatman No. 42 filter paper to give a clear filtrate. The filtrate was then evaporated to dryness in an oven (Memmert, Germany) at $40^{\circ} \mathrm{C}$. The percentage of cardiac glycoside content was calculated as below:

Percentage of cardiac glycoside (\%)

$$
=\frac{\text { Weight of residue }}{\text { Weight of the sample taken }} \times 100
$$

\section{Total flavonoid determination}

The method of Boham and Kocipai-Abyazan (1994) was used for the analysis of the flavonoids in C. nutans leaves and stems. About $10 \mathrm{~g}$ each of the dried leaves or stems was extracted with $100 \mathrm{~mL}$ of aqueous methanol (80\%) (SigmaAldrich, US) at room temperature. The extraction was repeated thrice. The solution was filtered with Whatman No. 42 filter paper $(125 \mathrm{~mm})$. The filtrate was heated to dry condition using a water bath (Memmert, Germany) $\left(65^{\circ} \mathrm{C}\right)$ until constant weight was obtained. The percentage of total flavonoid content was calculated as below:

\section{Percentage of total flavonoid (\%)}

$$
=\frac{\text { Weight of residue }}{\text { Weight of the sample taken }} \times 100
$$




\section{Total terpenoid determination}

The method of Fergusan (1956) was used for the determination of total terpenoids in the $C$. nutans leaves and stems. About two g each of the leaves or stems powders were mixed with 50mL of ethanol (95\%) (Sigma-Aldrich, US) for 24 hours. The mixture was collected after being filtered using Whatman No. 42 filter paper. The filtrate was extracted with petroleum ether (Sigma-Aldrich, US) at a temperature range of $60-80^{\circ} \mathrm{C}$ and was dried using a water bath (Memmert, Germany) $\left(65^{\circ} \mathrm{C}\right)$. The percentage of total terpenoid content was calculated as below:

\section{Percentage of total terpenoid (\%)}

$$
=\frac{\text { Weight of residue }}{\text { Weight of the sample taken }} \times 100
$$

\section{Total saponin determination}

The total saponin content was determined following the method of Makkat et al. (2007) based on vanillin-sulphuric acid colourimetric reaction. About $50 \mu \mathrm{L}$ of the $C$. nutans leaves or stems extract was mixed with $250 \mu \mathrm{L}$ of distilled water. Then, $250 \mu \mathrm{L}$ of vanillin reagent (Sigma-Aldrich, US) was added into the mixture. A $2.5 \mathrm{~mL}$ of sulphuric acid (72\%) (Sigma-Aldrich, US) was added into the mixture and mixed well. The solution mixture was kept in a water bath at $60 \pm$ $5^{\circ} \mathrm{C}$ for 10 mins before it was cooled down. The absorbance was determined at $544 \mathrm{~nm}$ wavelength using spectrophotometer (SPECTROstar Nano; Offenburg, Germany). The saponin value was indicated as diosgenin equivalents (mg DE/g of dried sample) derived from a standard curve. Standard was prepared by dissolving 0.1g of diosgenin in 10mL of 95\% ethanol (Sigma-Aldrich, US).

\section{Steroid determination}

The method of Devanaboyina et al. (2013) was adopted for the determination of steroids content in the $C$. nutans leaves and stems extracts. $100 \mu \mathrm{L}$ of the extract was mixed with $2 \mathrm{~mL}$ of sulphuric acid $\left(4 \mathrm{~N} ; 2 \mathrm{M} \mathrm{H}_{2} \mathrm{SO}_{4}\right)$ (Sigma-Aldrich, US) and $2 \mathrm{~mL}$ of iron (III) chloride (0.5\% w/v) (SigmaAldrich, US), followed by $0.5 \mathrm{~mL}$ of potassium hexacyanoferrate (III) solution (0.5\% w/v) (Sigma-Aldrich,
US). The solution mixture was kept in a water bath (Memmert, Germany) at $70 \pm 5^{\circ} \mathrm{C}$ for 30 mins. The absorbance was read at $780 \mathrm{~nm}$ wavelength using spectrophotometer (SPECTROstarNano; Offenburg, Germany). The value was expressed as cycloartenol equivalents (mg $\mathrm{CA} / \mathrm{g}$ of dried sample) derived from a standard curve. Standard was prepared by dissolving $1 \mathrm{~g}$ of cycloartenol in 10mL of 95\% ethanol (Sigma-Aldrich, US).

\section{Tannin determination}

The method of Siddhuraj and Manian (2007) was adopted to determine the tannin content in the $C$. nutans leaves and stems extracts. A total of $500 \mu \mathrm{L}$ of the extract was placed in the test tube separately. Then, 100mg of polyvinylpolypyrrolidone (Sigma-Aldrich, US) and 50o $\mu \mathrm{L}$ of distilled water was added to the extract. The mixture was vortexed using IKA@VORTEX 3 and incubated at $4^{\circ} \mathrm{C}$ for 15 mins. Then, the sample mixture was centrifuged (Kubota, Japan) at 5000 rpm for 5 mins. The supernatant was collected and kept in a vial before conducting the experiment. Only simple phenolic free of tannins was found in the supernatant (the tannins have been precipitated with the polyvinylpolypyrrolidone). The phenolic content of the supernatant was determined at $765 \mathrm{~nm}$ wavelength using spectrophotometer (SPECTROstarNano; Offenburg, Germany). The result was indicated as the content of free phenolic or non-tannin phenolic on a dry matter basis. The tannin content of the extracts was calculated as below:

Tannin (mg GAE/g sample) = total phenolics (mg GAE/g sample) - free phenolics (mg GAE/g sample).

\section{E. Determination of antioxidant properties in C. nutans leaves and stems}

\section{Determination of Folin-Ciocalteu Index (Total Phenolic Content, TPC)}

The method of Slinkard and Singleton (1977) was used for the TPC determination in C. nutans leaves and stems. A $0.1 \mathrm{~mL}$ of the leaves or stems extracts and gallic acid (standard curve) (Sigma-Aldrich, US) were added in a 96 deep well block. Then, $0.5 \mathrm{~mL}$ of diluted Folin-Ciocalteu reagent (Sigma-Aldrich, US) was added into mixture content in the 96 deep well block. The mixture was covered 
and kept at room temperature for 5 mins. $1 \mathrm{~mL}$ of sodium carbonate (7.5\%; w/v) (Sigma-Aldrich, US) was mixed with the mixture. A blue colour mixture was kept for 2 hours at room temperature. The absorbance was read at $765 \mathrm{~nm}$ wavelength using a spectrophotometer (SPECTROstarNano, Offenburg, Germany). The results were indicated as milligram of gallic acid equivalents to per gram of dried leaves and stem samples (mg GAE/ $\mathrm{g}$ of dried sample). Food additives for antioxidant such as $0.1 \mathrm{~g} / \mathrm{10mL}$ of butylated hydroxyanisole (BHA) and butylated hydroxytoluene (BHT) (Sigma-Aldrich, US) were used as a comparison with the plant extract mixtures. The same procedure was adopted for standard preparation.

\section{Determination of Ferric reducing/ antioxidant Power (FRAP)}

The method of Benzie and Strain (1996) was adopted to determine the FRAP content in $C$. nutans leaves and stems. FRAP reagent was ready using $300 \mathrm{mM}$ acetate buffer (Sigma-Aldrich, US)), pH3.6, 10mM TPTZ (2,4,6-tri (2pyridyl)-triazine) (Sigma-Aldrich, US) in 10mL of $40 \mathrm{mM}$ hydrochloric acid ( $\mathrm{HCl})$ (Sigma-Aldrich, US), and 20mM $\mathrm{FeCl}_{3} \cdot 6 \mathrm{H}_{2} \mathrm{O}$ (Sigma-Aldrich, US) in the ratio of 10:1:1 to serve as a working reagent. FRAP reagent (light brown colour) with the volume of $1 \mathrm{~mL}$ was prepared freshly and mixed with $100 \mu \mathrm{L}$ of $C$. nutans leave and stem samples or standards as a blank reagent. After 30 mins, the absorbance was determined at $595 \mathrm{~nm}$ wavelength using spectrophotometer (SPECTROstar ${ }^{N a n o}$ Offenburg, Germany). The result was indicated as $\mathrm{mg}$ of Trolox equivalents per gram of dried sample (mg TE/g of dried sample). Standard was prepared by dissolving $2 \mathrm{mg}$ of Trolox in 10mL of ethanol (Sigma-Aldrich, US). Food additives for antioxidant such as $0.1 \mathrm{~g} / 10 \mathrm{~mL}$ of BHA and BHT were used as the comparison with the plant extract mixtures.

\section{Determination of Radical-Scavenging Activity (DPPH)}

The method of Musa et al. (2011) was adopted. The decrease of the absorption at $516 \mathrm{~nm}$ wavelength of the 2, 2diphenyl-1-picrylhydrazyl (DPPH) solution (Sigma-Aldrich,
US) after the addition of the blank or sample extracts was determined via a spectrophotometer (SPECTROstarNano, Offenburg, Germany). 1mL of methanolic DPPH solution $(24 \mathrm{mg} / \mathrm{L})$ (purple colour) was added to $100 \mu \mathrm{L}$ of the sample solution (10mg/mL). Standard was prepared by dissolving $2 \mathrm{mg}$ of Trolox in 10mL of ethanol (Sigma-Aldrich, US). Food additives for antioxidant such as $0.1 \mathrm{~g} / 10 \mathrm{~mL}$ of BHA and BHT were used for comparison with the plant extract mixtures. The percentage of DPPH was calculated as below:

$$
\begin{aligned}
& \text { Radical scavenging activity } \\
& =\frac{\left[\text { Asb } 516 \mathrm{~nm}(t=0)-\text { Abs } 516 \mathrm{~nm}\left(t=t^{\prime}\right) \times 10\right]}{A b s 516 \mathrm{~nm}(t=0)}
\end{aligned}
$$

\section{F. Statistical Analysis}

The experiments were conducted in six replications. The results obtained were analysed using SPSS Version 22 (Chicago, Inc.) one-way ANOVA, Duncan's Multiple Range test with $\mathrm{P}<0.05$ and Pearson's correlation coefficient $(\mathrm{r})$.

\section{RESULT AND DISCUSSION}

\section{A. Preliminary qualitative phytochemical analysis of C. nutans leaves and stems}

Phytochemical studies were carried out on C. nutans leaves and stem that indicated the presence of alkaloids, flavonoids, glycosides, saponins, steroids, terpenoids, phenols and tannins in all samples. Ismail et al. (2017) stated that the environmental factors such as light intensity, temperature and soil characteristics ( $\mathrm{pH}$ of soil and type of planting soil) were influencing the presence and quantity of phenolic, flavonoids and antioxidant properties. The previous study on ethanol (50\%) leaves extract of $C$. nutans showed the presence of alkaloids, flavonoids, terpenoids, phenols and tannins (Aslam et al., 2016). However, methanol leaves extract of $C$. nutans only showed the presence of saponins, phenol, and flavonoids (Yang et al., 2013). The herbs plant Leucas indica (L) var. nagalapuramiana had the same medicinal functions with $C$. nutans; there were treating a snake bite, fever and swelling. Acetone extract of whole aerial part of these plants only contained alkaloids, phenols, flavonoids, steroids, saponins and tannins (Pranoothi et al., 
2014). Acetone leaves extract of lemongrass showed the presence of flavonoids and saponins (Geetha and Geetha, 2014). The methanol extract of medicinal plant Abrus precatorius, Dalbergia sissoo, Millettia pinnata and Tephrosia purpurea contained alkaloids, flavonoids, phenols, saponin, steroids and tannins (Gnanaraja et al.,
2014). Ethanol leaves extract of medicinal plant Phyllanthus amarus, Euphorbia heterophylla, Senna occidentalis, Piper nigrum and Ageratum conyzoides contained alkaloids, flavonoids, phenols, saponins and tannins (Ajuru et al., 2017).

Table 1. Total alkaloid, cardiac glycosides, flavonoid and terpenoid of various areas on Clinacanthus nutans leaves and stems

\begin{tabular}{|c|c|c|c|c|c|c|c|c|c|}
\hline \multirow{2}{*}{ Sample } & \multirow[b]{2}{*}{ Area } & \multicolumn{4}{|l|}{ Leaves (\%) } & \multicolumn{4}{|l|}{ Stems (\%) } \\
\hline & & Alkaloid & $\begin{array}{l}\text { Cardiac } \\
\text { glycoside }\end{array}$ & Flavonoid & Terpenoid & Alkaloid & $\begin{array}{l}\text { Cardiac } \\
\text { glycoside }\end{array}$ & Flavonoid & $\begin{array}{l}\text { Terpenoi } \\
\text { d }\end{array}$ \\
\hline YPL & $\begin{array}{l}\text { Un- } \\
\text { shaded }\end{array}$ & $8.40 \pm 2.11^{b}$ & $8.98 \pm 0.83^{b}$ & $\begin{array}{l}5.88 \pm 0.78 \\
b\end{array}$ & $2.41 \pm 0.17^{b}$ & $\begin{array}{l}\underset{b}{\mathrm{~b}} \\
4.83 \pm 2.27\end{array}$ & $11.13 \pm 1.78^{b}$ & $7.17 \pm 3.16^{b}$ & $\begin{array}{l}1.14 \pm 0.09 \\
b\end{array}$ \\
\hline \multirow{2}{*}{ YDC } & $\begin{array}{l}\text { Un- } \\
\text { Shaded }\end{array}$ & $10.14 \pm 2.40^{a}$ & $10.24 \pm 0.73$ & $\begin{array}{l}6.16 \pm 2.37 \\
\mathrm{a}\end{array}$ & $2.87 \pm 0.68^{a}$ & $\begin{array}{l}6.79 \pm 0.38 \\
\text { a }\end{array}$ & $13.84 \pm 0.66^{a}$ & $\begin{array}{l}9.03 \pm 2.28 \\
\text { a }\end{array}$ & $1.77 \pm 0.10$ \\
\hline & Shaded & $4.81 \pm 2.56^{c}$ & $9.76 \pm 1.25^{\mathrm{ab}}$ & $3.86 \pm 1.30$ & $2.30 \pm 0.70^{c}$ & $\begin{array}{l}2.53 \pm 1.54 \\
\mathrm{c}\end{array}$ & $\begin{array}{l}12.88 \pm 0.96 \\
\mathrm{ab}\end{array}$ & $\begin{array}{l}6.32 \pm 2.71 \\
\mathrm{c}\end{array}$ & $\begin{array}{l}0.98 \pm 0.22 \\
c\end{array}$ \\
\hline
\end{tabular}

a-c mean values with different superscripts in the same column are significantly different at $p<0.05$

\section{B. Quantitative phytochemical analysis of C. nutans leaves and stems}

\section{Total alkaloid determination}

Total alkaloid contents in leaves and stems parts of $C$. nutans exhibited higher contents in YDC un-shaded area with values of 10.14 and $6.79 \%$. The alkaloids content of leaves and stems samples were ranged between $4.81-10.14 \%$ and $2.53-6.79 \%$, respectively (Table 1). Ethanol leaves extract of medicinal plant P. amarus, E. heterophylla, $S$. occidentalis, $P$. nigrum and $A$. conyzoides contained alkaloids lower than the leaves sample of YDC un-shaded area (1.56, 7.15, 2.95, 0.67 and 9.40\% respectively) (Ajuru et al., 2017).

\section{Cardiac glycoside determination}

The cardiac glycoside contents of both leaves and stems parts of C. nutans were ranging between 8.98 and $13.84 \%$. The cardiac glycoside was high in stems samples than leaves samples. The YDC un-shaded stems contained the significant higher cardiac glycosides than others (Table 1). Chrysophyllum albidum was used in traditional medicine in treating diabetics, cancer and coronary heart disease and its seed kernel contained $1.88 \mathrm{~g} / 100 \mathrm{~g}$ or $1.88 \%$ cardiac glycosides, which is lower than current results (Muhammad and Abubakar, 2016).

\section{Total flavonoid determination}

The total flavonoid content was high in YDC un-shaded stems sample with a value of $9.03 \%$ followed with YPL unshaded, and YDC shaded stems samples with values of 7.17 and $6.32 \%$. The flavonoids content of leaves samples were ranging between $3.86-6.16 \%$ (Table 1). All leaves sample of C. nutans contained higher flavonoids than ethanol leaves extract of medicinal plant P. amarus, E. heterophylla, $S$. occidentalis and $P$. nigrum (1.62, 0.28, 1.16 and $0.57 \%$ respectively) (Ajuru et al., 2017). 
Table 2. Saponin, steroid and tannin contents of various areas on Clinacanthus nutans leaves and stems

\begin{tabular}{|c|c|c|c|c|c|c|c|}
\hline \multirow[t]{2}{*}{ Sample } & \multirow[t]{2}{*}{ Area } & \multicolumn{3}{|l|}{ Leaves } & \multicolumn{3}{|l|}{ Stems } \\
\hline & & $\begin{array}{l}\text { Saponin } \\
\text { (mg DE/ g) }\end{array}$ & $\begin{array}{l}\text { Steroid } \\
\text { (mg CA/g) }\end{array}$ & $\begin{array}{l}\text { Tannin } \\
\text { (mg GAE/g) }\end{array}$ & $\begin{array}{l}\text { Saponin } \\
\text { (mg DE/g) }\end{array}$ & $\begin{array}{l}\text { Steroid } \\
\text { (mg CA/g) }\end{array}$ & $\begin{array}{l}\text { Tannin } \\
\text { (mg GAE/g) }\end{array}$ \\
\hline YPL & $\begin{array}{l}\text { Un- } \\
\text { shaded }\end{array}$ & $67.12 \pm 0.60^{b}$ & $542.00 \pm 0.48^{c}$ & $453.49 \pm 1.05^{b}$ & $63.09 \pm 0.54^{c}$ & $158.75 \pm 2.16^{c}$ & $191.83 \pm 0.71^{b}$ \\
\hline \multirow[t]{2}{*}{ YDC } & $\begin{array}{l}\text { Un- } \\
\text { Shaded }\end{array}$ & $75.93 \pm 1.57^{a}$ & $634.72 \pm 0.90^{b}$ & $496.81 \pm 0.5^{a}$ & $65.10 \pm 2.11^{b}$ & $213.84 \pm 0.97^{b}$ & $204.35 \pm 1.57^{\mathrm{a}}$ \\
\hline & Shaded & $82.72 \pm 0.71^{a}$ & $833.3^{2} \pm 1.43^{a}$ & $340.12 \pm 2.53^{c}$ & $71.90 \pm 1.89^{a}$ & $247.35 \pm 1.38^{a}$ & $166.50 \pm 1.24^{c}$ \\
\hline
\end{tabular}

DE: diosgenin; CA: cycloartenol; GAE: gallic acid;

a-c mean values with different superscripts in the same column are significantly different at $p<0.05$

\section{Total terpenoid determination}

The total terpenoid contents of both leaves and stems of $C$. nutans ranged between 0.98 and $2.87 \%$. The total terpenoid content was high in the leaves samples than in the stems samples. YDC unshaded leaves contained the highest terpenoid content than the other samples (Table 1). Terpenoids played an important role in treating type 2 diabetes and cardiovascular diseases (Goto et al., 2010).

\section{Saponin determination}

The saponin content of $C$. nutans leaves and stems ranged between $67.12-82.72 \mathrm{mg} \mathrm{DE} / \mathrm{g}$ of dried leaves sample and $63.09-71.90 \mathrm{mg} \mathrm{DE} / \mathrm{g}$ of dried stems sample respectively. The YDC shaded leave and stem samples exhibited the highest saponin content (Table 2). The previous study on medicinal plant T. purpurea and D. sissoo contained saponins lower than the current result $(0.70$ and $0.12 \mathrm{mg} / \mathrm{g}$ of dry weight) (Gnanaraja et al., 2014).

\section{Steroid determination}

The steroid content of both leaves and stems of $C$. nutans ranged between $542.00-833.32 \mathrm{mg} \mathrm{CA} / \mathrm{g}$ of dried sample and $158.75-247.35 \mathrm{mg} \mathrm{CA} / \mathrm{g}$ of the dried sample respectively. The steroid content was high in the leave samples than in the stem samples. YDC shaded leaves contained significantly higher steroid content than the other samples (Table 2). The previous study on medicinal plant T. purpurea, Delonix regia and D. sissoo contained steroids lower than the current result (0.18, 0.17 and $0.11 \mathrm{mg} / \mathrm{g}$ of dry weight) (Gnanaraja et al., 2014).

\section{Tannin determination}

The tannin content of $C$. nutans leaves and stems ranged between 340.12 - 496.81mg GAE/g of dried samples and $166.50-204.35 \mathrm{mg} \mathrm{GAE} / \mathrm{g}$ of the dried sample, respectively. Un-shaded leaves samples from YDC showed a high amount of tannin (Table 2). The current result is higher than the previous study on lemongrass (3mg rutin/g of dried sample) (Geetha and Geetha, 2014). The previous study on medicinal plant T. purpurea, D. regia and D. sissoo contained tannins lower than the current result $(0.77,1.59$ and $0.52 \mathrm{mg} / \mathrm{g}$ of dry weight) (Gnanaraja et al., 2014).

\section{Determination of antioxidant properties in $C$. nutans leaves and stems}

Ali et al. (2008) claimed that natural anti-oxidants mainly present in the form of phenolic compounds such as flavonoids and phenolic acids from the plants. Un-shaded leaves sample of $C$. nutans from YDC exhibited significantly ( $\mathrm{p}<0.05$ ) higher result on antioxidant properties $(966 \mathrm{mg}$ GAE/g of dried sample in TPC, 20.44mg TE/g of dried sample in FRAP and $11.14 \mathrm{mg}$ TE/g of dried sample in DPPH) than the others (Table 3). The results were below the result of BHA and BHT (Table 4). The current TPC results on all leaves and stems samples were higher than the previous 
Table 3. Effect of different areas on the antioxidant activities of Clinacanthus nutans leaves and stems

\begin{tabular}{|c|c|c|c|c|c|c|c|}
\hline \multirow[b]{2}{*}{ Sample } & \multirow[b]{2}{*}{ Area } & \multicolumn{3}{|l|}{ Leaves } & \multicolumn{3}{|l|}{ Stems } \\
\hline & & $\begin{array}{l}\text { TPC } \\
\text { (mg GAE/g) }\end{array}$ & $\begin{array}{l}\text { FRAP } \\
\text { (mg TE/g) }\end{array}$ & $\begin{array}{l}\text { DPPH } \\
\text { (mg TE/g) }\end{array}$ & $\begin{array}{l}\text { TPC } \\
\text { (mg GAE/g) }\end{array}$ & $\begin{array}{l}\text { FRAP } \\
(\mathrm{mg} \mathrm{TE} / \mathrm{g})\end{array}$ & $\begin{array}{l}\text { DPPH } \\
\text { (mg TE/g) }\end{array}$ \\
\hline YPL & $\begin{array}{l}\text { Un- } \\
\text { shaded }\end{array}$ & $930.13 \pm 1.76^{b}$ & $14.00 \pm 0.26^{b}$ & $9.00 \pm 0.17^{b}$ & $209.86 \pm 2.44^{b}$ & $2.43 \pm 0.06^{b}$ & $1.27 \pm 0.05^{b}$ \\
\hline \multirow{2}{*}{ YDC } & $\begin{array}{l}\text { Un- } \\
\text { Shaded }\end{array}$ & $966.00 \pm 2.19^{a}$ & $20.44 \pm 0.06^{a}$ & $11.14 \pm 0.02^{a}$ & $249.08 \pm 2.59^{a}$ & $3.12 \pm 0.01^{a}$ & $1.79 \pm 0.02^{a}$ \\
\hline & Shaded & $661.89 \pm 2.31^{\mathrm{c}}$ & $6.55 \pm 0.01^{c}$ & $3.80 \pm 0.01^{c}$ & $207.62 \pm 1.26^{c}$ & $1.93 \pm 0.01^{\mathrm{c}}$ & $0.80 \pm 0.08^{c}$ \\
\hline
\end{tabular}

TPC: total phenolic content; GAE: gallic acid; FRAP: ferric-reducing antioxidant power; TE: trolox equivalent antioxidant capacity; DPPH: radical-scavenging activity

a-c mean values with different superscripts in the same column are significantly different at $p<0.05$

Table 4. Antioxidant power of butylated hydroxyanisole (BHA) and butylated hydroxytoluene (BHT)

\begin{tabular}{|l|l|l|l|}
\hline & TPC (mg GAE/g) & FRAP (mg TE/g) & DPPH(mg TE/g) \\
\hline BHA & TC & TC & $11.73 \pm 0.04$ \\
\hline BHT & $975.98 \pm 0.87$ & TC & $11.92 \pm 0.01$ \\
\hline
\end{tabular}

TPC: total phenolic content; GAE: gallic acid; FRAP: ferric-reducing antioxidant power; TE: trolox equivalent antioxidant capacity; DPPH: radical-scavenging activity

TC: too concentrated

study on ethanol (80\%) leaves and stems extract of $C$. nutans (117.00 and 114.42mg GAE/100g dried sample respectively) (Raya et al., 2015). Based on the previous results by Yang et al. (2013), methanolic extract of $C$. nutans leaves exhibited $1.77 \pm 0.01 \mathrm{mg}$ gallic acid equivalent/g, which was much lower than the current results. Furthermore, the water leaves extract of C. nutans (extraction time: one hour) showed lower in TPC result than the current result (46.71mg GAE/g of dried sample) (Kosai et al., 2016). Acetone extract of whole aerial part of herbs plant L. indica contained $0.35 \mathrm{mg}$ GAE/g of dried sample, which is lower than the acetone extract of $C$. nutans (Pranoothi et al., 2014).

In comparison between leaves and stems, leaves have a greater antioxidant potential than the stems. The same result was shown by an antioxidant study on bitter gourd (Momordica charantia) plant with the high antioxidative potential in leaves than stems in DPPH, FRAP and TPC (Kubola and Siriamornpun, 2008). The total phenol and total phenolic acid are found exhibiting higher antioxidative potential in leaves than the stems of herbal plant Moltkia petraea (Tratt.) Griseb (Končića et al., 2010). Leaf extract has higher total phenolic content (33.67mg GAE/g) than stem (11.11mg GAE/g) extracts determined by Wannes et al. (2010) on the methanolic extract of medicinal plant Myrtus communis L.

For comparison between un-shaded and shaded samples of YPL, both un-shaded leaves and stems samples exhibited higher $(\mathrm{p}<0.05)$ antioxidant activity than shaded samples. High light exposure promoted high phenolic content than under low light condition, hence exhibited high antioxidant activity. Gregoriou et al. (2007) have reported that photosynthetic capacity was lowered due to shading. Furthermore, the duration of storage might be one of the factors that were affecting TPC. The previous study showed decreasing trend on TPC result of leaves of $C$. nutans from one day to four days of storage (Raya et al., 2015).

\section{Correlation coefficient of antioxidant activities}

There was the highest correlation (0.995) between the results of FRAP and DPPH of C. nutans leaves and stems, while it showed the lowest value (0.945) between TPC and FRAP (Table 5). 
Table 5. Correlation coefficient of antioxidant activities of total phenolic content (TPC), ferric-reducing antioxidant power (FRAP) and DPPH radical scavenging activity

\begin{tabular}{|l|l|l|}
\hline $\begin{array}{l}\text { Correlation } \\
\text { coefficient (r) }\end{array}$ & FRAP & DPPH \\
\hline TPC & 0.945 & 0.959 \\
\hline FRAP & & 0.995 \\
\hline
\end{tabular}

Total phenolic content (TPC), ferric-reducing antioxidant power (FRAP) and DPPH radical scavenging activity Correlation is significant at the 0.01 level (2-tailed)

\section{CONCLUSION}

The results showed the presence of various phytochemical compounds in $C$. nutans leaves and stems. These phytochemical compounds contributed to its antioxidant properties. Hence, C. nutans has the potential to become an alternative antioxidant source in a food product or for the development of functional food products. In future work, specific types of phytochemical compounds which present in leaves and stems can be investigated.

\section{ACKNOWLEDGEMENT}

The authors wish to thank Universiti Kebangsaan Malaysia for funding assistance: FRGS/1/2014/STWNo3/UKM/02/1 and DIP-2014-007.

\section{REFERENCES}

[1] Abaoba, OO \& Efuwape, BM 2001, 'Antibacterial properties of some Nigerian species', Biology Research Communications, vol. 13, pp. 183-188.

[2] Ajuru, MG, Williams, LF \& Ajuru, G 2017, 'Qualitative and quantitative phytochemical screening of some plants used in ethnomedicine in the Niger Delta region of Nigeria', Journal of Food and Nutrition Sciences, vol. 5, no. 5, pp. 198-205.

[3] Ali, SS, Kasoju, N, Luthra, A, Singh, A, Sharanabassava, H \& Sahu, A 2008, 'Indian medicinal as source of antioxidants', Food Research International, vol. 41, pp. 1-15.

[4] Arullappan, S, Rajamanickam, P, Thevar, N \& Kodimani, CC 2014, 'In vitro screening of cytotoxic, antimicrobial and antioxidant activities of Clinacanthus nutans (Acanthaceae) leaf extracts', Tropical Journal of Pharmaceutical Research, vol. 13, no. 9, pp. 1455-1461.

[5] Aslam, MS, Ahmad, MS \& Mamat, AS 2016, 'Phytochemical evaluation of polyherbal formulation of Clinacanthus nutans and Elephantopus scaber to identify flavonoids', Pharmacognosy Journal, vol. 8, no. 6, pp. 534-541.
[6] Benzie, IF \& Strain, JJ 1996, 'The ferric reducing ability of plasma (FRAP) as a measure of antioxidant power the frap assay', Analytical Biochemistry, vol. 239, pp. 70-76.

[7] Bohm, BA \& Kocipai-Abyazan, R 1994, 'Flavonoids and condensed tannins from the leaves of Vaccinum raticulation and Vaccinum calyimium', Pacific Science, vol. 48, pp. 458-463.

[8] De-Ruiz, REL, Fusco, RMD, Angela, S \& Sohar, OR 2001, 'Isolation of flavonoids and anthraquinones of Amaranthus muricatus (Moquin) ex Hicken (Amarathaceae)', Acta Farm Bonaer, vol. 20, pp. 9-12.

[9] Devanaboyina, N, Ramalakshmi, N, Satyanarayana, Sudeepthi, P, Hemachakradhar K \& Pavankumarraju N 2013, 'Preliminary phytochemical screening, quantitative estimation and evaluation of antimicrobial activity of Alstonia macrophylla stem bark', International Journal of Science Inventions Today, vol. 2, no. 1, pp. 31 - 39 .

[10] El-olemy, MM, Al-muhtadi, FJ \& Affi, AFA 1994, Experimental Phytochemical: A Laboratory Manual, King Saud University Press, Saudi Arabia.

[11] Elegani, AA, Al-nima, MSEI \& Muddathir, AK 
2002, 'Antimicrobial activity of some species of the family Combretaceae', Phytotherapie Research, vol. 16 , pp. 551-561.

[12] Ferguson, NM 1956, Pharmacognosy, Mac Millan Company, p. 191.

[13] Fong, SY, Piva, T, Urban, S \& Huynh, T 2015, 'Genetic homogeneity of vegetatively propagated Clinacnathus nutans (Acanthaceae)', Journal of Medicinal Plant Research, vol. 8, no. 25, pp. 903914.

[14] Gao, C, Huang, XX, Bai, M, Wu, J, Li, JY, Liu, QB, Li, LZ \& Song, SJ 2015, 'Anti-inflammatory sesquiterpene pyridine alkaloids from Tripterygium wilfordii', Fitoterapia, vol. 9, pp. 49 -54 .

[15] Geetha, TS \& Geetha, N 2014, 'Phytochemical screening, quantitative analysis of primary and secondary metabolites of Cymbopogan citratus (DC) stapf. leaves from Kodaikanal hills, Tamilnadu', International Journal of PharmTech Research, vol. 6, no. 2, pp. 521-529.

[16] Gnanaraja, R, Prakash, V \& Peter, S 2014, 'Qualitative and quantitative phytochemicals analysis of selected fabaceae medicinal plants from Allahabad region', The Pharma Innovation Journal, vol. 3, no. 7, pp. 53-56.

[17] Goto, T, Takahashi, N, Hirai, S \& Kawada, T 2010, Various terpenoids derived from herbal and dietary plants function as PPAR modulators and regulate carbohydrate and lipid metabolism, PPAR Research, pp. 1-9.

[18] Gregoriou, K, Pontikis, K \& Vemmos, S 2007, 'Effects of reduced irradiance on leaf morphology, photosynthetic capacity, and fruit yield in olive (Olea europaea L.)', Photosynthetica, vol. 45, pp. 172-181.

[19] Harborne, JB 1984, Phytochemical methods- a guide to modern techniques of plant analysis, 2nd edn, Chapman and Hall, London.

[20] Harborne, JB 1973, Methods of plant analysis. Phytochemical methods, Chapman and Hall, London.

[21] Hassan, KZ, Noor, HM \& Kader, J. 2015,
'Antibacterial efficacy of three different extracts of Polygonum minus (Huds.)', in International Conference on Waste Management, Ecology and Biological Sciencess, Kuala Lumpur, Malaysia.

[22] Hemwimon, S, Pavasant, P \& Shotipruk, A 2007 , 'Microwave-assisted extraction of antioxidative anthraquinones from roots of Morinda citrifolia', Separation and Purification Technology, vol. 54, pp. 44-50.

[23] Ismail, NZ, Arsad, H, Samian, MR \& Hamdan MR 2017, 'Determination of phenolic and flavonoid contents, antioxidant activities and GC-MS analysis of Clinacanthus nutans (Acanthaceae) in different locations', AGRIVITA Journal of Agricultural Science, vol. 39, no. 3, pp. 335-344.

[24] Končića, MZ, Kremera, D, Gruzb, J, Strnadb, M, Biševaca, G, Kosaleca, I, Šamecc, D, PiljacŽegaracc, J \& Karlovićd, K 2010, 'Antioxidant and antimicrobial properties of Moltkia petraea (Tratt.) Griseb. flower, leaf and stem infusions', Food and Chemical Toxicology, vol. 48, no. 6,pp. 1537-1542.

[25] Kosai, P, Sirisidthi, K \& Jiraungkoorskul, W 2016, 'Evaluation of total phenolic compound and cytotoxic activity of Clinacanthus nutans', Indian Journal of Pharmaceutical Sciences, vol. 78, no. 2, pp. 283-286.

[26] Kristeller, JL, Jankowski, A \& Reinaker, T 2014, 'Role of corticosteroids during cardiopulmonary bypass', Hospital Pharmacy, vol. 49, no. 3, pp. 232-236.

[27] Kubola, J \& Siriamornpun, S 2008, 'Phenolic contents and antioxidant activities of bitter gourd (Momordica charantia L.) leaf, stem and fruit fraction extracts in vitro', Food Chemistry, vol. 110, no. 4, pp. 881-890.

[28] Liu, L, Chen, YY, Qin, XJ, Wang, B, Jin, Q, Liu, YB \& Luo, XZ 2015, 'Antibacterial monoterpenoid indole alkaloids from Alstonia scholaris cultivated in temperate zone', Fitoterapia, vol. 9, pp. 160-164.

[29] Makkar, HP, Siddhuraju, P \& Becker, K 2007, Methods in molecular biology: plant secondary metabolites, Totowa, Human Press.

[30] Maldonado, PD, Barrera, D, Rivero, I, Mata, R, 
Medina-Campos, ON, Hernández-Pando, R \& Pedraza-Chaverrí, J 2003, 'Antioxidant sallylcysteine prevents gentamicin-induced oxidative stress and renal damage', Free Radical Biology and Medicine, vol. 35, pp. 317-324.

[31] Mohanta, TK, Patra, JK, Rath, SK, Pal, DK \& Thatoi, HN 2007, 'Evaluation of antimicrobial activity and phytochemical screening of oils and nuts of Semicarpus anacardium L., Scientific Research and Essay, vol. 2, no. 11, pp. 486-490.

[32] Muhammad, SA \& Abubakar, SM 2016, 'Qualitative and quantitative determination of phytochemicals in aqueous extract of Chrysophyllum albidum seed kernel', Biosciences Biotechnology Research Asia, vol. 13, no. 2. DOI: http://dx.doi.org/10.13005/bbra/2153

[33] Musa, KH, Abdullah, A, Jusoh, K \& Subramaniam, V 2011, 'Antioxidant activity of pink-flesh guava (Psidium guajava L.): effect of extraction techniques and solvents', Food Analysis Methods, vol. 4, pp. 100-107.

[34] Okuda, T, Yoshida, T \& Hatano, T 1995 'Hydrolyzable tannins and related polyphenols', Progress in Chemistry Organic Natural Product, vol. 66, pp. 1-177.

[35] Othira, JO, Onek, LA, Deng, LA \& Omolo, EO 2009, 'Insecticidal potency of Hyptis spicigera preparations against Sitophilus zeamais I and Tribolium castaneum (herbst) on stored maize grains', African Journal of Agricultural Research, vol. 4 , no. 3 , pp. 187-192.

[36] Prakash, D, Dhakarey, R \& Mishra, A 2004, 'Carotenoids: the phytochemicals of nutraceutical importance', Indian Journal of Agricultural Biochemistry, vol. 17, pp. 1-8.

[37] Pranoothi, EK, Narendra, K, Joshi, DSDS, Swathi, J, Sowjanya, KM, Rathnakarreddi, KVN, Emmanuel, SJ, Padmavathi, C \& Satya, AK 2014, 'Studies on qualitative, quantitative, phytochemical analysis and screening of in vitro biological activities of Leucas indica (L) var. nagalapuramiana', International Journal of Herbal Medicine, vol. 2, no. 3, pp. 30-36.
[38] Raya, KB, Ahmad, SH, Farhana, SF, Mohammad, M, Tajidin, NE \& Parvez, A 2015, 'Changes in phytochemical contents in different parts of Clinacanthus nutans (Burm. F.) lindau due to storage duration', Bragantia, vol. 74, no. 4, pp. $445-452$

[39] Sakdarat, S, Shuyprom, A, Pientong, C, Ekalaksananan, T \& Thongchai, S 2009, 'Bioactive constituents from the leaves of Clinacanthus nutans Lindau', Bioorganic \& Medicinal Chemistry, vol. 17 , pp. 1857-186o.

[40] Siddhuraju, P \& Manian, S 2007, 'The antioxidant activity and free radical scavenging capacity of dietary phenolic extract from horse gram (Macrotyloma uniflorum (Lam.) Verdc.) seeds', Food Chemistry, vol. 105, no. 3, pp. 950-958.

[41] Siew, YY, Zareisedehizadeh, S, Seetoh, WG, Neo, SY, Tan, CH \& Koh, HL 2014, 'Ethnobotanical survey of usage of fresh medicinal plants in Singapore', Journal of Ethnopharmacology, vol. 155 , no. 3, pp. $1450-1466$.

[42] Slinkard, K \& Singleton, V 1977, 'Total phenol analysis; automation and comparison with manual methods', American Journal of Enology and Viticulture, vol. 28, pp. 49-55.

[43] Sofowora, A 1993, Medicinal plants and traditional medicine in Africa, 2nd edn, Spectrum Books Limited, Ibadan.

[44] Stefanović, OD, Tešić, JD \& Čomić, LR 2015, 'Melilotus albus and Dorycnium herbaceum extracts as source of phenolic compounds and their antimicrobial, antibiofilm, and antioxidant potentials', Journal of Food and Drug Analysis, vol. 23 , no. 3 , pp. 417-424.

[45] Trease, G \& Evans, SM 2002, Pharmacognosy, 15th edn, Bailer Tindal, London.

[46] Wannes, WA, Mhamdi, B, Sriti, J, Jemia, MB, Ouchikh, O, Hamdaoui, G, Kchouk, ME \& Marzouk, B 2010, 'Antioxidant activities of the essential oils and methanol extracts from Myrtle (Myrtus communis var. italica L.) leaf, stem and flower', Food and Chemical Toxicology, vol. 48, no. 5, pp. $1362-1370$ 
[47] Xie, JH, Dong, CJ, Nie, SP, Li, F, Wang, ZJ, Shen, MY \& Xie, MY 2015, 'Extraction, chemical composition and antioxidant activity of flavonoids from Cyclocarya paliurus (Batal.) Iljinskaja leaves', Food Chemistry, vol. 186, pp. 97-105.

[48] Yamamoto, Y \& Gaynor, RB 2002, 'Therapeutic potential of inhibitory of the NF-KB pathway in the treatment of inflammation and cancer', Journal of Clinical Investigation, vol. 1, pp. 493503.

[49] Yang, HS, Peng, TW, Madhavan, P, Shukkoor, MSA \& Akowuah, GA 2013, 'Phytochemical analysis and antibacterial activity of methanolic extract of Clinacanthus nutans leaf', International Journal of Drug Development and Research, vol. 5, no. 3, pp. 349-355.

[50] Zwadyk, P 1992, Enteriobactericeae in Zinsser microbiology, 2oth edn, Gerogthieme Verlag, Stuggart. 